\title{
Gastrointestinal and Liver Manifestations in COVID-19 Population
}

\begin{abstract}
Saad Saleem ${ }^{1, *}$, Rizwan Ishtiaq ${ }^{2}$, Faisal Inayat ${ }^{3}$, Muhammad Aziz $^{4}$, Wissam Bleibel ${ }^{2}$
1. Department of Internal Medicine, Sunrise

Hospital and Medical Center, Las Vegas, NV, United States

2. Department of Internal Medicine, St. Vincent Mercy Medical Center, Toledo, OH, United States

3. Allama Iqbal Medical College, Lahore, Pakistan

4. Division of Gastroenterology and Hepatology, University of Toledo Medical Center, Toledo, $\mathrm{OH}$, United States

\section{ABSTRACT}

The coronavirus was first identified as the cause of pneumonia in Wuhan, a town in the Hubei Province of China, in December 2019. It usually has respiratory symptoms such as myalgia, headache, cough, and dyspnea. In the medical literature, digestive symptoms and liver disease have been reported in Coronavirus disease in 2019 (COVID-19) patients. In this review article, we summarized the recent studies of gastrointestinal and hepatic manifestations and management of COVID-19. The most common gastrointestinal symptoms were poor appetite/anorexia, nausea/vomiting, diarrhea, and abdominal pain. Elevated aminotransferase has been reported in patients with COVID-19. COVID-19 gastrointestinal and hepatic management is usually symptomatic except for high-risk populations such as patients with inflammatory bowel disease or autoimmune hepatitis, which require special attention.
\end{abstract}

\footnotetext{
*orresponding Author:

Saad Saleem, MD

3186 S Maryland Pkway, Las Vegas, NV 89109, United States
}

Tel: +17029615000

Fax: +17029615010

Email: saadsaleem29@gmail.com

Received: 07 Feb. 2021

Accepted: 29 Aug. 2021

\section{KEYWORDS:}

Gastrointestinal; Liver; COVID-19; Coronavirus

Please cite this paper as:

Saleem S, Ishtiaq R, Inayat F, Aziz M, Bleibel W. Gastrointestinal and Liver Manifestations in COVID-19 Population. Middle East J Dig Dis 2021;13:281-286. doi: 10.34172/mejdd.2021.236

Coronavirus was identified as the cause of pneumonia in Wuhan, a town in the Hubei Province of China, in December 2019. In February 2020, the World Health Organization designated the disease as Coronavirus disease 2019 (COVID-19). ${ }^{1}$ Although the true prevalence of asymptomatic cases is unknown, a literature review estimated that it was as high as 30$40 \%$ based on population-based testing. ${ }^{2}$ COVID-19 usually spreads through respiratory droplets; however, fecal excretion of the virus has also been shown to be a source of transmission. ${ }^{3}$

Symptomatic COVID-19 patients usually have headaches, myalgia, fever, cough, and dyspnea. ${ }^{4}$ Patients with COVID-19 usually have typical respiratory signs and symptoms, but gastrointestinal (GI) symptoms and liver involvement have been reported in the course of the illness. In this review article, we assessed the GI and hepatic manifestations and management of COVID-19 using the available medical literature.

\section{Gastrointestinal and hepatic manifestation}

Diarrhea and vomiting are the most common GI symptoms in patients with COVID-19. ${ }^{5}$ In a meta-analysis involving 4.434 patients with COVID-19, the prevalence of GI symptoms was 11.51 percent,

\section{INTRODUCTION}


with the most common symptoms being diarrhea (7.78\%), nausea/vomiting (3.57\%), poor appetite $(2.39 \%)$, and abdominal pain $(0.78 \%){ }^{6}$ Although, patients with COVID-19 and unusual GI symptoms such as dysentery ${ }^{7}$ or pure hyperbilirubinemia ${ }^{8}$ have been observed.

The clinical acute flare-up of chronic GI diseases - Crohn's disease and ulcerative colitis may have symptoms similar to those of COVID- $19,{ }^{9}$ including nausea, vomiting, diarrhea, and anorexia. ${ }^{10}$ Physicians need to assess whether the symptoms are related to the acute flare-up of underlying disease or COVID-19. Therefore, COVID-19 should be excluded in these patients.

It is uncertain whether patients with chronic liver disease (CLD) are more susceptible to COVID, but in the absence of immunosuppression, it is not known to be associated with an increased risk of COVID-19. ${ }^{11}$ It has been shown that COVID-19 uses the angiotensin-covering enzyme 2 (ACE2) receptor for entry, and ACE2 is highly expressed in the GI tract. ${ }^{12}$ The liver may be more susceptible to COVID-19 (SARS-CoV-2 virus) due to ACE2 receptors in the biliary and epithelial cells. ${ }^{13}$ COVID binds to ACE2 receptors to gain entry and damage the target organ. ${ }^{14}$ Medical literature has shown that pre-existing liver disease has been associated with a worse outcome in patients with COVID-19 associated with increased mortality compared with those without the liver disease. ${ }^{15}$

Elevated aminotransferase has been reported in hospitalized COVID-19 patients. ${ }^{15}$ Aspartate transaminase (AST) and alanine transaminase (ALT) are usually less than five times the upper limit of normal; however, higher levels of aminotransferase and severe acute hepatitis have also been reported..$^{16,17}$ Predictors of peak abnormal liver enzymes include age, male sex, diabetes mellitus, drugs (e.g., hydroxychloroquine, remdesivir), and inflammatory markers (IL-6, ferritin).$^{18}$ AST is higher than ALT, and this pattern is associated with disease severity. ${ }^{19,20}$ AST and ALT are more commonly elevated than bilirubin and alkaline phosphatase, although ACE2 receptors are more commonly expressed on cholangiocytes than hepatocytes.
One possible explanation could be that COVID may have a different pathogenesis mechanism other than the ACE2 receptor. In a series of 48 autopsies, hepatic pathology showed evidence of hepatic vascular involvement of focal portal and lobular lymphocytic infiltrates. ${ }^{21}$ It can also be explained by the paternity of AST and ALT elevation. AST is higher concrete in zone three of the liver, and damages to this zone may result in greater alteration of the level of AST.22 Zone 3 of the liver is closer to the central vein, so COVID may have an effect on the organ's vascular function. The other explanation could be higher AST, which might reflect a non-hepatic source of injury. ${ }^{19}$

A large multinational study has shown that COVID-19 can be the underlying cause of hepatic decompensation in patients with liver cirrhosis who have no respiratory symptoms at the time of diagnosis of COVID-19. ${ }^{23}$ This study showed that baseline liver disease severity is strongly associated with COVID-19 related morbidity and mortality, with far greater mortality than in patients with cirrhosis admitted because of influenza. ${ }^{24}$ Clinicians should therefore maintain a low threshold for COVID-19 tests for hepatic decompensation in patients with liver cirrhosis.

\section{Diagnosis}

COVID-19 testing is recommended for the following patients with GI symptoms: first, hospitalized patients with new-onset of GI symptoms; second, patients with new-onset of GI symptoms for more than 48 hours; thirdly, patients with chronic GI disorders (e.g., inflammatory bowel disease [IBD]) with symptoms suggestive of disease flare up..$^{25}$

\section{Management}

The management of COVID-19 digestive symptoms is mainly supportive therapy to prevent complications. For patients with nausea and vomiting, antiemetics drugs can relieve the symptoms, and oral or intravenous hydration should be encouraged to prevent electrolyte imbalance. Antidiarrheal agent, loperamide, may be used after other infectious causes of diarrhea have been ruled out. 
Medical literature has shown that patients with IBD are not at higher risk for COVID-19 and should continue maintenance therapy to sustain remission. ${ }^{26-28}$ They may require the addition or escalation of antiinflammatory or biologic therapy for symptomatic improvement and remission. ${ }^{28}$ However, if systemic glucocorticoids are required, a lower dose and a shorter period of time should be used to induce remission. ${ }^{28}$

Patients with IBD who became ill with COVID-19 may require adjusting IBD medications based on the severity of IBD, COVID-19, and underlying comorbidities of the patient. ${ }^{29}$ They may require a reduction in immunosuppression during active COVID-19 to prevent complications. ${ }^{30}$ According to American Gastroenterological Association (AGA) expert opinion, patients with IBD who develop COVID-19, should stop thiopurines, methotrexate, tofacitinib, and biological therapy. ${ }^{31}$ In contrast, in a study including 200 individuals who were already on immunosuppressive medications for IBD, it was found that these patients had a lower risk of infection and less COVID-19 symptoms. ${ }^{32}$

There was a multinational study conducted to estimate the risk of COVID-19 with different IBD drugs. It included 1439 cases from 47 countries that showed that combination therapy with tumor necrosis factor (TNF) antagonist and thiopurine was associated with an increased risk of severe COVID-19 compared with TNF antagonist monotherapy or thiopurine monotherapy. ${ }^{33}$ Mesalamine/ sulfasalazine was also associated with an increased risk of COVID-19 compared with no mesalamine/ sulfasalazine use. ${ }^{33}$ There is no medical literature on the resumption of IBD therapy after COVID-19, although expert consensus has been reached that drugs (e.g., biologic therapies) held during symptomatic infection can be resumed after symptoms have been resolved. ${ }^{31}$

For the management of IBD during COVID pandemic, the American Gastroenterology Association (AGA) updated guidance recommends that an emergency endoscopic assessment be carried out only if it will change the patient's management. ${ }^{28}$ Elective endoscopic procedures should be delayed in order to reduce COVID-19 transmission. GI bleeding is a common indication for endoscopy, but some centers have suggested medical treatment for suspected nonvariceal upper GI bleeding to prevent COVID-19 spread. ${ }^{34}$ In a series of six patients with acute upper GI bleeding, they were managed medically, including intravenous proton pump inhibitor (PPI) PPIwithout the need for urgent endoscopy. ${ }^{35}$

Similarly, in patients with COVID-19 and lower GI bleeding, the endoscopic assessment may be delayed initially and then performed on an outpatient basis after the acute illness has been resolved. ${ }^{34}$ There were no identifiable risk factors for GI bleeding, but those patients who developed GI bleeding during hospitalization were associated with increased mortality. ${ }^{36}$ The use of anticoagulation or antiplatelet medication was not associated with an increased risk of GI bleeding in patients with COVID-19. ${ }^{36}$

Liver injury in mild COVID-19 cases is usually temporary and does not require specific treatment beyond supportive care. ${ }^{19}$ The approach for patients with autoimmune hepatitis (AIH) and COVID-19 is to reduce immunosuppression during active viral disease by lowering the risk of COVID-19-related complications while balancing the risk of disease flare-up. ${ }^{37}$ In patients with chronic hepatitis B and COVID-19, reactivation of HBV infection has been observed in patients treated with glucocorticoids and tocilizumab. HBV prophylaxis may be indicated when these therapies are initiated. ${ }^{38-40}$

For liver transplant recipients without COVID-19, reducing immunosuppression is not recommended, as it may increase the risk of developing acute rejection. ${ }^{41}$ For such patients with moderate to severe COVID-19, the immunosuppression dose is lowered to reduce the risk of superinfection. In patients using calcineurin inhibitors, drug levels are monitored one to two times a week or as outlined in transplant center-specific protocols due to the risk of acute kidney injury. ${ }^{19}$

PPI users were more likely than non-users to report a positive COVID-19 test, and the risk increased with increasing dose..$^{42}$ The use of histamine2-receptor antagonists (H2RA) was not associated with increased risk. ${ }^{42}$ Although the exact mechanism of how PPI reduces the risk of COVID-19 is not known, it could be explained that less acidic gastric $\mathrm{pH}$ with 
PPI therapy does not inactivate the virus. ${ }^{43}$ PPIs should be used only when indicated, at the lowest effective dose for the disease. ${ }^{43}$

According to the current guidelines of the Centers for Disease Control and Prevention, the decision to discontinue transmission should be based on negative results of rRT-PCR testing for SARS-CoV-2 from at least two sequential respiratory tract specimens collected $>24$ hours apart. ${ }^{44}$ Xiao and colleagues, in a study on 73 patients, showed that in more than $20 \%$ of the patients with SARS-CoV-2, viral RNA remained positive in the feces, even after a negative respiratory viral RNA test. This indicates that viral GI infection and potential fecal-oral transmission may last after viral clearance in the respiratory tract. ${ }^{12}$

\section{Complications}

In a single-center study involving 184 patients, COVID-19-related ARDS was associated with a higher risk of GI complications compared with non-COVID-19-related ARDS, including increased aminotransferase levels and higher ileus, and intestinal ischemia. ${ }^{24}$

\section{Prognosis}

Data showed that patients with COVID-19 and diarrheal symptoms were associated with a better prognosis. ${ }^{45-47}$ In a cohort study involving 190 patients hospitalized with COVID-19, diarrhea symptoms were associated with $62 \%$ lower risk of in-hospital mortality compared with the absence of diarrhea. ${ }^{47}$ In a cohort study involving 84 patients with COVID-19 pneumonia, stool samples from patients with diarrhea had higher rates of real-time polymerase chain detection of SARS-CoV-2 compared with patients without diarrhea (69\% vs. $17 \%){ }^{45}$

\section{CONCLUSION}

Patients with COVID-19 may have GI and liver involvement, with the most common symptoms being diarrhea, nausea/vomiting, poor appetite, and abdominal pain. Liver abnormalities, including elevated AST and ALT, have been reported in hospitalized patients with COVID-19. The management of the digestive symptoms of COVID-19 is mainly supportive therapy for the prevention of complications. Highrisk populations, including patients with IBD, liver transplantation, or AIH, may require reduction or discontinuation in their immunosuppression therapy based on the severity of their illness.

\section{ETHICAL APPROVAL}

There is nothing to be declared.

\section{CONFLICT OF INTEREST}

The authors declare no conflict of interest related to this work.

\section{REFERENCES}

1. World Health Organization. Director-General's remarks at the media briefing on 2019-nCoV on 11 February 2020. http://www.who.int/dg/speeches/detail/who-director-generals-remarks-at-the-media-briefing-on-2019-ncov-on-11-february-2020.

2. Oran DP, Topol EJ. Prevalence of Asymptomatic SARSCoV-2 Infection: A Narrative Review. Ann Intern Med 2020;173:362. doi: 10.7326/M20-3012.

3. Wu Y, Guo C, Tang L, Hong Z, Zhou J, Dong X, et al. Prolonged presence of SARS-CoV-2 viral RNA in faecal samples. Lancet Gastroenterol Hepatol 2020;5:434-5. doi: 10.1016/S2468-1253(20)30083-2.

4. Stokes EK, Zambrano LD, Anderson KN, Marder EP, Raz KM, El Burai Felix S, et al. Coronavirus Disease 2019 Case Surveillance-United States, January 22-May 30, 2020. MMWR Morb Mortal Wkly Rep 2020;69:759-65. doi: 10.15585/mmwr.mm6924e2.

5. Abbasinia M, Hormati A, Eshagh Hossaini SK, Foroghi Ghomi SY, Zamani F, Afifian M, et al. Clinical Manifestations of Gastrointestinal Symptoms in COVID-19 Patients: An Integrative Review. Gastroenterol Nurs 2021;44:E1-E10. doi:10.1097/SGA.0000000000000584.

6. Merola E, Armelao F, de Pretis G. Prevalence of gastrointestinal symptoms in coronavirus disease 2019: a meta-analysis. Acta Gastroenterol Belg 2020;83:603-15.

7. Hormati A, Ghadir MR, Saeidi M, Aminnejad R, Khodadust F, Afifian M, et al. Dysentery as a rare GI symptom found in COVID-19 patients. Gastroenterol Hepatol 2021;44:314. doi: 10.1016/j.gastrohep.2020.06.005.

8. Hormati A, Ghadir MR, Saeidi M, Aminnejad R, Afifian M, Ahmadpour S. Hepatic involvement as Hyperbilirubinemia in Patients with COVID-19: Case Series from Iran. Infect Disord Drug Targets 2021. doi: 10.2174/18715265216662 10218201601.

9. Occhipinti V, Pastorelli L. Challenges in the Care of IBD Patients During the CoViD-19 Pandemic: Report From a "Red Zone" Area in Northern Italy. Inflamm Bowel Dis 2020;26:793-6. doi: 10.1093/ibd/izaa084. 
10. Tariq R, Saha S, Furqan F, Hassett L, Pardi D, Khanna S. Prevalence and Mortality of COVID-19 Patients With Gastrointestinal Symptoms: A Systematic Review and Meta-analysis. Mayo Clin Proc 2020;95:1632-48. doi: 10.1016/j.mayocp.2020.06.003.

11. Zhang C, Shi L, Wang FS. Liver injury in COVID-19: management and challenges. Lancet Gastroenterol Hepatol 2020;5:428-30. doi: 10.1016/S2468-1253(20)30057-1.

12. Xiao F, Tang M, Zheng X, Liu Y, Li X, Shan H. Evidence for Gastrointestinal Infection of SARS-CoV-2. Gastroenterology 2020;158:1831-3.e3. doi: 10.1053/j.gastro.2020.02.055.

13. Chai X, Hu L, Zhang Y, Han W, Lu Z, Ke A, et al. ACE2 Expression in Cholangiocytes May Cause Liver Damage After 2019-nCoV Infection. bioRxiv 2020 doi. org/10.1101/2020.02.03.931766

14. Wang D, Hu B, Hu C, Zhu F, Liu X, Zhang J, et al. Clinical Characteristics of 138 Hospitalized Patients With 2019 Novel Coronavirus-Infected Pneumonia in Wuhan, China. JAMA 2020;323:1061-9. doi: 10.1001/jama.2020.1585. Erratum in: JAMA 2021;325:1113.

15. Singh S, Khan A. Clinical Characteristics and Outcomes of Coronavirus Disease 2019 Among Patients With Preexisting Liver Disease in the United States: A Multicenter Research Network Study. Gastroenterology 2020;159:768-71.e3. doi: 10.1053/j.gastro.2020.04.064.

16. Chen N, Zhou M, Dong X, Qu J, Gong F, Han Y, et al. Epidemiological and clinical characteristics of 99 cases of 2019 novel coronavirus pneumonia in Wuhan, China: a descriptive study. Lancet 2020;395:507-13. doi:10.1016/ S0140-6736(20)30211-7.

17. Richardson S, Hirsch JS, Narasimhan M, Crawford JM, McGinn T, Davidson KW, et al. Presenting Characteristics, Comorbidities, and Outcomes Among 5700 Patients Hospitalized With COVID-19 in the New York City Area. JAMA 2020;323:2052-9. doi: 10.1001/jama.2020.6775. Erratum in: JAMA. 2020 May 26;323(20):2098.

18. Fix OK, Hameed B, Fontana RJ, Kwok RM, McGuire BM, Mulligan DC, et al. Clinical Best Practice Advice for Hepatology and Liver Transplant Providers During the COVID-19 Pandemic: AASLD Expert Panel Consensus Statement. Hepatology 2020;72:287-304. doi: 10.1002/ hep. 31281 .

19. Huang C, Wang Y, Li X, Ren L, Zhao J, Hu Y, et al. Clinical features of patients infected with 2019 novel coronavirus in Wuhan, China. Lancet 2020;395:497-506. doi: 10.1016/ S0140-6736(20)30183-5. Epub 2020 Jan 24. Erratum in: Lancet 2020.

20. Lei F, Liu YM, Zhou F, Qin JJ, Zhang P, Zhu L, et al. Longitudinal Association Between Markers of Liver Injury and Mortality in COVID-19 in China. Hepatology 2020;72:389-98. doi: 10.1002/hep.31301.

21. Sonzogni A, Previtali G, Seghezzi M, Alessio MG, Gianatti A, Licini L, et al. Liver and COVID 19 infection: A very preliminary lesson learnt from histological post-mortem findings in 48 patients. Preprints 2020, 2020040438. doi:10.20944/preprints202004.0438.v1.

22. Giannini EG, Testa R, Savarino V. Liver enzyme alteration: a guide for clinicians. CMAJ 2005;172:367-79. doi: 10.1503/ cmaj.1040752.

23. Moon AM, Webb GJ, Aloman C, Armstrong MJ, Cargill T, Dhanasekaran R, et al. High mortality rates for SARS$\mathrm{CoV}-2$ infection in patients with pre-existing chronic liver disease and cirrhosis: Preliminary results from an international registry. J Hepatol 2020;73:705-8. doi: 10.1016/j. jhep.2020.05.013. Epub 2020 May 21.

24. Schütte A, Ciesek S, Wedemeyer H, Lange CM. Influenza virus infection as precipitating event of acute-on-chronic liver failure. J Hepatol 2019;70:797-9. doi: 10.1016/j. jhep.2018.11.015.

25. Sultan S, Altayar O, Siddique SM, Davitkov P, Feuerstein JD, Lim JK, et al. AGA Institute Rapid Review of the Gastrointestinal and Liver Manifestations of COVID-19, Meta-Analysis of International Data, and Recommendations for the Consultative Management of Patients with COVID-19. Gastroenterology 2020;159:320-34.e27. doi: 10.1053/j.gastro.2020.05.001.

26. Mao R, Liang J, Shen J, Ghosh S, Zhu LR, Yang H, et al. Implications of COVID-19 for patients with pre-existing digestive diseases. Lancet Gastroenterol Hepatol 2020;5:425-7. doi: 10.1016/S2468-1253(20)30076-5. Epub 2020 Mar 11. Erratum in: Lancet Gastroenterol Hepatol 2020;5:e6.

27. Norsa L, Indriolo A, Sansotta N, Cosimo P, Greco S, D'Antiga L. Uneventful Course in Patients With Inflammatory Bowel Disease During the Severe Acute Respiratory Syndrome Coronavirus 2 Outbreak in Northern Italy. Gastroenterology 2020;159:371-2. doi: 10.1053/j.gastro.2020.03.062.

28. Rubin DT, Feuerstein JD, Wang AY, Cohen RD. AGA Clinical Practice Update on Management of Inflammatory Bowel Disease During the COVID-19 Pandemic: Expert Commentary. Gastroenterology 2020;159:350-7. doi: 10.1053/j.gastro.2020.04.012.

29. D'Amico F, Peyrin-Biroulet L, Danese S. Inflammatory Bowel Diseases and COVID-19: The Invisible Enemy. Gastroenterology 2020;158:2302-4. doi: 10.1053/j.gastro.2020.04.032.

30. Zhou F, Yu T, Du R, Fan G, Liu Y, Liu Z, et al. Clinical course and risk factors for mortality of adult inpatients with COVID-19 in Wuhan, China: a retrospective cohort study. Lancet 2020;395:1054-62. doi: 10.1016/S01406736(20)30566-3. Epub 2020 Mar 11. Erratum in: Lancet 2020;395: 1038 .

31. https://gastro.org/news/how-to-treat-ibd-patients-duringthe-pandemic/ (Accessed on June 19, 2020).

32. Hormati A, Ghadir MR, Zamani F, Khodadadi J, Khodadust $\mathrm{F}$, Afifian M, et al. Are there any association between COVID-19 severity and immunosuppressive therapy? Immunol Lett 2020;224:12-13. doi: 10.1016/j.imlet.2020.05.002. 
33. Ungaro RC, Brenner EJ, Gearry RB, Kaplan GG, Kissous-Hunt $\mathrm{M}$, Lewis JD, et al. Effect of IBD medications on COVID-19 outcomes: results from an international registry. Gut 2021;70:725-32. doi: 10.1136/gutjnl-2020-322539.

34. Sethi A, Swaminath A, Latorre M, Behin DS, Jodorkovsky D, Calo D et al. Donning a New Approach to the Practice of Gastroenterology: Perspectives From the COVID-19 Pandemic Epicenter. Clin Gastroenterol Hepatol 2020;18:1673-81. doi: 10.1016/j.cgh.2020.04.032.

35. Cavaliere K, Levine C, Wander P, Sejpal DV, Trindade AJ. Management of upper GI bleeding in patients with COVID-19 pneumonia. Gastrointest Endosc 2020;92:454-5. doi: 10.1016/j. gie.2020.04.028.

36. Trindade AJ, Izard S, Coppa K, Hirsch JS, Lee C, Satapathy SK. Northwell COVID-19 Research Consortium. Gastrointestinal bleeding in hospitalized COVID-19 patients: a propensity score matched cohort study. J Intern Med 2021;289:887-94. doi: 10.1111/joim.13232.

37. Gerussi A, Rigamonti C, Elia C, Cazzagon N, Floreani A, Pozzi R, et al. Coronavirus Disease 2019 (COVID-19) in autoimmune hepatitis: a lesson from immunosuppressed patients. Hepatol Commun 2020;4:1257-62. doi: 10.1002/hep4.1557. Epub ahead of print.

38. Reddy KR, Beavers KL, Hammond SP, Lim JK, Falck-Ytter YT, American Gastroenterological Association Institute. American Gastroenterological Association Institute guideline on the prevention and treatment of hepatitis B virus reactivation during immunosuppressive drug therapy. Gastroenterology 2015;148:215-9; quiz e16-7. doi: 10.1053/j.gastro.2014.10.039. Epub 2014 Oct 31. Erratum in: Gastroenterology 2015;148:455. multiple investigator names added.

39. Chen LF, Mo YQ, Jing J, Ma JD, Zheng DH, Dai L. Shortcourse tocilizumab increases risk of hepatitis B virus reactivation in patients with rheumatoid arthritis: a prospective clinical observation. Int $J$ Rheum Dis 2017;20:859-69. doi: 10.1111/1756-185X.13010. Epub 2017 Feb 3.

40. Ekpanyapong S, Reddy KR. Hepatitis B Virus Reactivation: What Is the Issue, and How Should It Be Managed? Clin Liver Dis 2020;24:317-33. doi: 10.1016/j.cld.2020.04.002.

41. Phipps MM, Verna EC. Coronavirus Disease 2019 and Liver Transplantation: Lessons from the First Year of the Pandemic. Liver Transpl 2021;27:1312-25. doi: 10.1002/lt.26194.

42. https://www.cdc.gov/coronavirus/2019-ncov/need-extra-precautions/groups-at-higher-risk.html.

43. Almario CV, Chey WD, Spiegel BMR. Increased Risk of COVID-19 Among Users of Proton Pump Inhibitors. Am J Gastroenterol 2020;115:1707-15. doi: 10.14309/ajg.0000000000000798.

44. Centers for Disease Control and Prevention. Available from: https://www.cdc.gov/coronavirus/2019-ncov/hcp/dispositionhospitalized-patients.html. (January 2021)

45. Wei XS, Wang X, Niu YR, Ye LL, Peng WB, Wang ZH, et al. Diarrhea Is Associated With Prolonged Symptoms and Viral Carriage in Corona Virus Disease 2019. Clin Gastroenterol Hepatol 2020;18:1753-59.e2. doi: 10.1016/j.cgh.2020.04.030.
46. Tian Y, Rong L, Nian W, He Y. Review article: gastrointestinal features in COVID-19 and the possibility of faecal transmission. Aliment Pharmacol Ther 2020;51:843-51. doi: 10.1111/apt.15731.

47. Schettino M, Pellegrini L, Picascia D, Saibeni S, Bezzio C, Bini F, et al. Clinical Characteristics of COVID-19 Patients With Gastrointestinal Symptoms in Northern Italy: A Single-Center Cohort Study. Am J Gastroenterol 2021;116:306-10. doi: 10.14309/ajg.0000000000000965. PMID: 33009054. 